\title{
Does zygosity influence the metabolic profile of twins? A population based cross sectional study
}

\author{
Pernille Poulsen, Allan Vaag, Henning Beck-Nielsen
}

\begin{abstract}
Objective To study the influence of zygosity on the metabolic variables involved in the pathophysiology of type 2 diabetes.

Design Population based cross sectional study. Setting Odense University Hospital, Denmark. Participants 125 monozygotic twin pairs and 178 dizygotic twin pairs of the same sex born between 1921 and 1940.
\end{abstract}

Main outcome measures Clinical characteristics of monozygotic and dizygotic twins with or without a family history of type 2 diabetes.

Results Absolute prevalences of type 2 diabetes and impaired glucose tolerance according to the World Health Organisation criteria were similar in both the monozygotic and the dizygotic twins as were measurements of height, weight, body mass index, waist to hip ratio, and fasting plasma glucose and insulin concentrations. During the oral glucose tolerance test, monozygotic twins had a higher incremental plasma insulin area under the curve than dizygotic twins (10.05 (SD 0.68) v 9.89 (0.72) $\mathrm{pmol} / \mathrm{l} \times$ minutes, $\mathrm{P}<0.01)$ indicating insulin resistance. In twins with normal glucose tolerance and without first degree relatives or co-twins with type 2 diabetes or impaired glucose tolerance, both the glucose and insulin areas under the curve were higher among monozygotic twins (glucose 214.4 (88.3) $v$ 189.8 (78.4) $\mathrm{mmol} / \mathrm{l} \times$ minutes, $\mathrm{P}<0.05$; insulin 20040 (14 865-32 554) v 17625 (12 330-23 640) $\mathrm{pmol} / \mathrm{l} \times$ minutes, $\mathrm{P}=0.08)$.

Conclusion Zygosity influences both plasma glucose and plasma insulin concentrations during an oral glucose tolerance test. This supports an intrauterine influence on glucose homeostasis and perhaps on insulin resistance in humans.

\section{Introduction}

Several epidemiological and metabolic studies have shown a strong association between low birth weight and the development of type 2 diabetes later in life. ${ }^{1-4}$ Our finding of lower birth weights among monozygotic twins with type 2 diabetes compared with their genetically identical non-diabetic co-twins eliminates the possibility that the association is solely due to a putative genotype susceptibility to type 2 diabetes and a genetically determined low birth weight. ${ }^{4-6}$ The association between type 2 diabetes and low birth weight may be due to an adverse intrauterine environment-for example, intrauterine malnutrition.

Intrauterine malnutrition is more likely to occur in twins because they share their uterine environment, and therefore they have lower birth weights than singletons. ${ }^{7}$ Around two thirds of monozygotic twins are monochorionic - that is, they share a placenta. The sharing of the same nutritive source, and the development of vascular anastamoses between monochorionic twins, results in a different and possibly more adverse environment than that of dichorionic monozygotic and dizygotic twins - that is, twins having separate placentas. ${ }^{78}$ According to the "thrifty phenotype hypothesis," sharing a placenta may influence metabolic variables permanently. ${ }^{9}$ Monozygotic twins may therefore exhibit various metabolic abnormalities and have different prevalences of disease than dizygotic twins. The validity of twin studies investigating a possible genetic cause of a phenotype for which intrauterine factors are known has therefore been questioned. ${ }^{10}$

\section{Participants and methods}

\section{Participants}

We identified twins through the Danish twin register. ${ }^{41-13}$ In November 1994, we sent a postal questionnaire to monozygotic twin pairs and dizygotic twin pairs of the same sex, who were alive according to the records of the civil registry. We included 3074 monozygotic and dizygotic twins (1537 pairs) born in Funen county, Denmark between 1931 and 1940 (aged 55 to 64 years) or born anywhere in Denmark between 1921 and 1930 (aged 65 to 74 years).

We asked the twins whether they had diabetes and, if so, we requested information on age at onset of the disease, use of insulin, and duration of insulin use. We asked each twin whether they were willing to participate in a study of diabetes using a standard oral glucose tolerance test and measurement of anthropometric factors.

Overall, 975 twin pairs responded to the questionnaire of which 303 twin pairs (31.1\%) participated in the clinical examination; these were similar for age and self reported prevalence of diabetes to the group of twins who were not clinically examined. ${ }^{13}$ We established zygosity with the similarity method by asking the twins about physical similarities and mistaken identity. ${ }^{11}$ This method has been evaluated by comparison with serological zygosity testing, and it has a misclassification rate of less than $5 \% .{ }^{11}$ Overall, 125 twin pairs were monozygotic and 178 twin pairs were dizygotic.

Our study was approved by the regional ethics committees, and it was conducted according to the principles of the Helsinki Declaration.

\section{Methods}

The participants underwent a standardised oral glucose tolerance test with $75 \mathrm{~g}$ of glucose after an overnight fast for 10-12 hours. We took a sample of peripheral venous blood before the participants ingested the glucose then 30 minutes and 2 hours later. We analysed plasma glucose concentrations by the glucose dehydrogenase oxidation method, and we measured plasma insulin concentrations using a two site, two step, time resolved immunofluorimetric assay (DELFIA) as previously described. ${ }^{15}$ We calculated

\author{
Department of \\ Endocrinology and \\ Internal Medicine, \\ Odense University \\ Hospital, DK-5000 \\ C Odense, \\ Denmark \\ Pernille Poulsen, \\ research fellow \\ Henning \\ Beck-Nielsen, \\ professor \\ Department of \\ Endocrinology, \\ Hvidovre Hospital, \\ DK-2650 Hvidovre, \\ Denmark \\ Allan Vaag, \\ consultant \\ Correspondence to: \\ P Poulsen \\ p.poulsen@ \\ winsloew.ou.dk
}

BMJ 1999;319:151-4 
incremental glucose and insulin areas under the curves with the trapezoidal method. Cross reactivities with proinsulin, C peptide, and Des(31,32)-split product in the insulin assay were all less than $0.4 \%$. In the physiological ranges for plasma insulin, the intra-assay coefficients of variation were $3.6 \%-4.3 \%$ and the interassay coefficients of variation were $1.7 \%-3.4 \%$. Waist circumference was measured midway between the lowest rib and the iliac crest with a tape measure in standing participants. Hip circumference was measured over the widest part of the gluteal region, and the waist to hip ratio was calculated.

Table 1 Prevalence ( $95 \%$ confidence interval) of type 2 diabetes and glucose tolerance among 250 monozygotic and 356 dizygotic twins

\begin{tabular}{llcc} 
Twins & Type 2 diabetes & $\begin{array}{c}\text { Impaired } \\
\text { glucose tolerance }\end{array}$ & $\begin{array}{c}\text { Normal } \\
\text { glucose tolerance }\end{array}$ \\
\hline Monozygotic & $14.4(10.1$ to 18.7$)$ & $18.8(13.8$ to 23.7$)$ & $66.6(60.7$ to 72.5$)$ \\
\hline Dizygotic & $12.1(8.8$ to 15.4$)$ & $23.0(18.7$ to 27.3$)$ & $64.9(60.0$ to 69.8$)$ \\
\hline Total & $13.1(10.4$ to 15.8$)$ & $21.3(18.0$ to 24.6$)$ & $65.7(62.0$ to 69.4$)$ \\
\hline
\end{tabular}

Table 2 Clinical characteristics and plasma glucose and insulin concentrations from oral glucose tolerance test in monozygotic and dizygotic twins. Values are mean (SD) unless stated otherwise

\begin{tabular}{|c|c|c|c|c|}
\hline Variable & $\begin{array}{l}\text { Monozygotic } \\
\text { twins }(n=250)\end{array}$ & $\begin{array}{l}\text { Dizygotic twins } \\
\qquad(\mathrm{n}=356)\end{array}$ & $\begin{array}{l}\text { Difference of mean } \\
(95 \% \mathrm{CI})\end{array}$ & $P$ value \\
\hline No of males & 124 & 172 & & \\
\hline Age (years) & $67.0(4.7)$ & $66.3(5.1)$ & $0.8(-0.03$ to 1.6$)$ & 0.06 \\
\hline Height $(\mathrm{cm})$ & $165.6(9.6)$ & $166.5(9.1)$ & $-0.9(-2.4$ to 0.6$)$ & 0.26 \\
\hline Weight (kg) & $71.6(14.0)$ & $72.0(13.5)$ & $-0.3(-2.6$ to 1.9$)$ & 0.77 \\
\hline Body mass index $\left(\mathrm{kg} / \mathrm{m}^{2}\right)$ & $26.0(4.4)$ & $25.9(4.3)$ & $0.1(-0.6$ to 0.8$)$ & 0.72 \\
\hline Weight to hip ratio & $0.88(0.08)$ & $0.87(0.09)$ & $0.009(-0.006$ to 0.02$)$ & 0.23 \\
\hline \multicolumn{5}{|c|}{ Plasma glucose concentration $(\mathrm{mmol} / \mathrm{l})$ : } \\
\hline 0 minutes & $6.1(1.6)$ & $6.1(1.7)$ & $0.04(-0.23$ to 0.31$)$ & 0.78 \\
\hline 30 minutes & $9.9(2.4)$ & $9.6(2.7)$ & $0.29(-0.12$ to 0.71$)$ & 0.17 \\
\hline 120 minutes & $8.0(4.3)$ & $7.8(4.3)$ & $0.19(-0.51$ to 0.89$)$ & 0.59 \\
\hline Area under curve* & $309.9(175.3)$ & $289.4(194.8)$ & $20.5(-9.85$ to 50.8$)$ & 0.16 \\
\hline \multicolumn{5}{|c|}{ Log of plasma insulin concentration $(\mathrm{pmol} / \mathrm{l})$ : } \\
\hline 0 minutes & $3.70(0.55)$ & $3.65(0.53)$ & $0.05(-0.04$ to 0.14$)$ & 0.27 \\
\hline 30 minutes & $5.57(0.68)$ & $5.43(0.66)$ & $0.14(0.03$ to 0.25$)$ & $<0.05$ \\
\hline 120 minutes & $5.44(0.80)$ & $5.34(0.81)$ & $0.10(-0.03$ to 0.23$)$ & 0.14 \\
\hline Area under curve* & $10.05(0.68)$ & $9.89(0.72)$ & $0.16(0.04$ to 0.27$)$ & $<0.01$ \\
\hline
\end{tabular}

${ }^{*}$ Minutes $\times$ concentration

Table 3 Clinical characteristics and plasma glucose and insulin concentrations from oral glucose tolerance test in monozygotic and dizygotic twins with normal glucose tolerance. Values are mean (SD) unless stated otherwise

\begin{tabular}{|c|c|c|c|c|}
\hline Variable & $\begin{array}{l}\text { Monozygotic } \\
\text { twins }(n=134)\end{array}$ & $\begin{array}{c}\text { Dizygotic } \\
\text { twins }(n=162)\end{array}$ & $\begin{array}{l}\text { Difference of mean } \\
(95 \% \mathrm{CI})\end{array}$ & $P$ value \\
\hline No of males & 68 & 74 & & \\
\hline Age (years) & $65.9(4.8)$ & $65.2(5.3)$ & $0.7(-0.5$ to 1.8$)$ & 0.26 \\
\hline Height (cm) & $167.5(9.5)$ & $167.1(8.7)$ & $0.5(-1.6$ to 2.6$)$ & 0.66 \\
\hline Weight $(\mathrm{kg})$ & $71.0(13.1)$ & $70.3(12.6)$ & 0.7 (-2.3 to 3.6$)$ & 0.65 \\
\hline Body mass index $\left(\mathrm{kg} / \mathrm{m}^{2}\right)$ & $25.2(3.9)$ & $25.1(3.4)$ & $0.15(-0.69$ to 0.98$)$ & 0.73 \\
\hline Weight to hip ratio & $0.87(0.08)$ & $0.85(0.09)$ & $0.02(0.0006$ to 0.04$)$ & $<0.05$ \\
\hline \multicolumn{5}{|c|}{ Plasma glucose concentration $(\mathrm{mmol} / \mathrm{l})$ : } \\
\hline 0 minutes & $5.6(0.5)$ & $5.5(0.5)$ & $0.07(-0.04$ to 0.19$)$ & 0.21 \\
\hline 30 minutes & $9.1(1.6)$ & $8.5(1.4)$ & $0.61(0.27$ to 0.94$)$ & $<0.001$ \\
\hline 120 minutes & $5.8(1.1)$ & $5.8(1.0)$ & $-0.04(-0.28$ to 0.20$)$ & 0.73 \\
\hline Area under curve ${ }^{\star}$ & $213.7(88.8)$ & $186.9(80.3)$ & 26.8 (7.5 to 46.2$)$ & $<0.01$ \\
\hline \multicolumn{5}{|c|}{ Log of plasma insulin concentration (pmol/l): } \\
\hline 0 minutes & $3.57(0.49)$ & $3.50(0.45)$ & $0.07(-0.04$ to 0.18$)$ & 0.21 \\
\hline 30 minutes & $5.65(0.66)$ & $5.4(0.57)$ & 0.24 (0.10 to 0.39$)$ & $<0.001$ \\
\hline 120 minutes & $5.09(0.72)$ & $5.13(0.71)$ & $-0.04(-0.21$ to 0.12$)$ & 0.59 \\
\hline Area under curve* & $9.97(0.63)$ & $9.81(0.56)$ & $0.16(0.02$ to 0.30$)$ & $<0.05$ \\
\hline
\end{tabular}

Type 2 diabetes was defined as diabetes diagnosed after the age of 40 years and current treatment with antidiabetic drugs or diet, or both, according to WHO criteria $^{16}$; a fasting venous plasma glucose concentration $\geqslant 7.8 \mathrm{mmol} / 1$ or a venous plasma glucose concentration of $\geqslant 11.1 \mathrm{mmol} / 12$ hours after loading, or both. Impaired glucose tolerance was defined as a fasting venous plasma glucose concentration less than 7.8 $\mathrm{mmol} / \mathrm{l}$ and a venous plasma glucose concentration between $7.8 \mathrm{mmol} / \mathrm{l}$ and $11.1 \mathrm{mmol} / \mathrm{l} 2$ hours after loading. Participants with neither type 2 diabetes nor impaired glucose tolerance were considered to have normal glucose tolerance.

\section{Statistical analysis}

To reduce skewness we performed logarithmic transformations on the insulin data. The transformations yielded approximately normal distributions. We compared monozygotic and dizygotic twins by parametric analysis ( $t$ test) for unpaired data. All tests were two tailed, and $\mathrm{P} \leqslant 0.05$ was considered significant.

\section{Results}

The prevalence of both type 2 diabetes and impaired glucose tolerance was similar in the 250 monozygotic twins and 356 dizygotic twins (table 1). No significant differences were found in height, weight, body mass index, or waist to hip ratio between both groups of twins (table 2). Fasting plasma insulin concentrations were similar in both groups. In the monozygotic twins, plasma glucose concentration at 30 minutes and incremental glucose area under the curve were nonsignificantly higher than in the dizygotic twins, and the monozygotic twins had higher plasma insulin concentrations at 30 minutes and 2 hours than dizygotic twins. Only the difference in plasma insulin concentration at 30 minutes reached statistical significance. The insulin area under the curve was significantly higher among monozygotic than dizygotic twins (10.05 (SD 0.68) $v$ 9.89 (0.72), $\mathrm{P}<0.01)$.

\section{Twins concordant for normal glucose tolerance}

We excluded 58 monozygotic twin pairs as one or both twins had either impaired glucose tolerance or type 2 diabetes. In the remaining 67 monozygotic twin pairs (134 individuals) both twins had normal glucose tolerance. We excluded 87 dizygotic twin pairs in which one or both twins had impaired glucose tolerance or type 2 diabetes, leaving 81 dizygotic twin pairs with normal glucose tolerance. Table 3 shows the characteristics of the monozygotic and dizygotic twins concordant for normal glucose tolerance. These twins had similar heights, weights, and body mass indices, but the monozygotic twins had a significantly higher waist to hip ratio and a higher plasma glucose concentration at 30 minutes (although similar at 0 and 2 hours) than the dizygotic twins. We found no difference in fasting plasma insulin concentrations between both groups of twins. The monozygotic twins had significantly higher plasma insulin concentrations at 30 minutes and significantly higher incremental glucose and insulin areas under the curves than dizygotic twins.

Twins without first degree relatives with diabetes To avoid differences in genetic predisposition among the two groups of twins, we excluded 26 monozygotic 
twins and 28 dizygotic twins with normal glucose tolerance and a first degree relative with diabetes. We compared the remaining 108 monozygotic and 134 dizygotic twins with normal glucose tolerance and without first degree relatives with diabetes (table 4). Both groups of twins had similar heights, weights, body mass indices, and waist to hip ratios. The monozygotic twins had significantly higher plasma glucose and insulin concentrations at 30 minutes than the dizygotic twins. Plasma glucose and insulin concentrations both at fasting and at 2 hours were similar in the two groups. The monozygotic twins had higher incremental glucose and insulin areas under the curve than the dizygotic twins.

\section{Discussion}

The differences we found between the monozygotic and dizygotic twins can not be explained by a larger prevalence of diabetes related genes among the monozygotic twins, as the differences persisted after exclusion of both twins with glucose intolerance and those with glucose tolerance with first degree diabetic relatives. Excluding a genetic cause of the observed differences between the two groups, and assuming a comparable postnatal environment, differences may be attributed to factors in the intrauterine environment. This agrees with findings of lower birth weights and higher perinatal mortality and morbidity among monozygotic than dizygotic twins. ${ }^{7}$ Mothers of dizygotic twins are likely to be older than mothers of monozygotic twins, which might explain some of the differences between the groups. We are unaware of any evidence relating maternal age to the metabolic profile of twins during an oral glucose tolerance test.

\section{Low birth weight}

Several studies have proposed an association between low birth weight due to intrauterine malnutrition and the development of type 2 diabetes. ${ }^{1-4}$ Associations have been shown between the pathophysiological mechanisms (low insulin secretion and peripheral insulin resistance) leading to type 2 diabetes and low birth weight in humans, ${ }^{17-20}$ and rats experiencing protein deficiency in utero. ${ }^{21-25}$ Monozygotic twins would, therefore, be expected to have a more abnormal insulin secretion or greater insulin resistance than dizygotic twins owing to exposure to a more adverse intrauterine environment. We were unable to show a lower insulin secretion (plasma insulin concentration 30 minutes after loading) among monozygotic than dizygotic twins. On the contrary, the monozygotic twins had higher plasma glucose and insulin concentrations in the oral glucose tolerance tests indicating insulin resistance. This supports reports of an association between an adverse intrauterine environment and the development of insulin resistance. ${ }^{18-20}{ }^{26}$ Our finding also agrees with studies showing an association between fetal growth retardation and low birth weight and plasma glucose concentration 30 minutes after loading. ${ }^{26-29}$

\section{Twin studies}

The classic twin model of concordances and heritabilty indices is used in the assessment of the effects of genetic and environmental factors on a given
Table 4 Clinical characteristics and plasma glucose and insulin concentrations from oral glucose tolerance test in monozygotic and dizygotic twins with normal glucose tolerance and no first degree diabetic relatives. Values are mean (SD) unless stated otherwise

\begin{tabular}{lcccr} 
Variable & $\begin{array}{c}\text { Monozygotic } \\
\text { twins }(\mathbf{n = 1 0 8})\end{array}$ & $\begin{array}{c}\text { Dizygotic } \\
\text { twins }(\mathbf{n = 1 3 4 )}\end{array}$ & $\begin{array}{c}\text { Difference of mean (95\% } \\
\text { Cl) }\end{array}$ & P value \\
\hline No of males & 54 & 66 & & \\
\hline Age (years) & $65.6(5.0)$ & $65.0(5.3)$ & $0.6(-0.7$ to 1.9$)$ & 0.38 \\
\hline Height $(\mathrm{cm})$ & $168.1(9.5)$ & $167.4(8.6)$ & $0.7(-1.6$ to 3.0$)$ & 0.55 \\
\hline Weight $(\mathrm{kg})$ & $71.3(13.5)$ & $70.3(12.3)$ & $1.1(-2.2$ to 4.3$)$ & 0.53 \\
\hline Body mass index $\left(\mathrm{kg} / \mathrm{m}^{2}\right)$ & $25.2(4.1)$ & $25.0(3.4)$ & $0.2(-0.7$ to 1.2$)$ & 0.67 \\
\hline Weight to hip ratio & $0.86(0.08)$ & $0.85(0.09)$ & $0.01(-0.007$ to 0.036$)$ & 0.20 \\
\hline Plasma glucose concentration $(\mathrm{mmo} / \mathrm{l}):$ & & & \\
\hline 0 minutes & $5.6(0.5)$ & $5.6(0.5)$ & $0.02(-0.11$ to 0.14$)$ & 0.77 \\
\hline 30 minutes & $9.0(1.5)$ & $8.5(1.3)$ & $0.47(0.11$ to 0.83$)$ & $<0.02$ \\
\hline 120 minutes & $5.8(1.1)$ & $5.8(1.0)$ & $-0.03(-0.30$ to 0.24$)$ & 0.81 \\
\hline Area under curve & $214.4(88.3)$ & $189.8(78.4)$ & $24.6(3.45$ to 45.7$)$ & $<0.05$ \\
\hline Log of plasma insulin concentration $(\mathrm{pmol} / \mathrm{l}):$ & & & \\
\hline 0 minutes & $3.53(0.51)$ & $3.49(0.47)$ & $0.05(-0.08$ to 0.17$)$ & 0.47 \\
\hline 30 minutes & $5.60(0.67)$ & $5.37(0.57)$ & $0.23(0.07$ to 0.39$)$ & $<0.01$ \\
\hline 120 minutes & $5.03(0.64)$ & $5.12(0.72)$ & $-0.08(-0.26$ to 0.09$)$ & 0.34 \\
\hline Area under curve & $9.92(0.60)$ & $9.79(0.57)$ & $0.13(-0.02$ to 0.28$)$ & 0.08 \\
\hline
\end{tabular}

${ }^{*}$ Minutes $\times$ concentration.

phenotype, because monozygotic twins are genetically identical whereas dizygotic twins have only $50 \%$ of their genes in common like singleton siblings. A greater similarity between monozygotic twin pairs has been interpreted as evidence of a genetic influence. The classic twin model is based on the assumption that environmental covariance both prenatally and postnatally is the same for both monozygotic and dizygotic twin pairs.

The differences we found between both groups of twins challenges the assumption of a similar intrauterine environment for both groups, and to some extent questions the validity of the classic twin approach, but only to the extent that the investigated phenotype has an intrauterine aetiological factor. Our results are primarily of importance for twin studies of diabetes and possibly insulin resistance and related disorders (the metabolic syndrome).

Despite the significant difference in the glucose area under the curve between the monozygotic and dizygotic twins-monozygotic twins being more hyperglycaemic-the prevalences of type 2 diabetes and impaired glucose tolerance were similar in both groups. The presence of type 2 diabetes and impaired glucose tolerance are, however, primarily based on plasma glucose concentrations at fasting and 2 hours after loading. Similar prevalences may be explained by the lack of significant differences in plasma glucose concentrations at these times between the two groups of twins. Also, the finding of similar plasma glucose and insulin concentrations at these times indirectly validates our previous conclusions of gene versus environment in studies of diabetes in monozygotic and dizygotic twins. ${ }^{13}$

\section{Conclusion}

Our findings support an intrauterine factor in the control of glucose homeostasis and perhaps the severity of insulin resistance in twins. Our findings may question the validity of the classic twin approach, where an equal environment is assumed for both monozygotic and dizygotic twins. Future studies are required to confirm 
Key messages

- Zygosity affects glucose homeostasis and insulin resistance but has no influence on body weight and fat distribution

- Differences in glucose metabolism between monozygotic and dizygotic twins are independent of a family history of type 2 diabetes

- The validity of causal conclusions from classic twin studies may be questioned

the presence of a lower insulin action in monozygotic compared with dizygotic twins.

Contributors: PP coordinated and performed the clinical reference study and participated in the study design, data collection, analyses, interpretation, and writing of the paper. PP and AV conceived the original idea for the study; they will act as guarantors for the paper. AV participated in the study design, data analyses, interpretation, and revising and editing the paper. HB-N initiated the clinical reference study, participated data interpretation, and revised and edited the paper.

Funding: The Novo Nordisk Foundation, the Clinical Research Institute, Odense University, the Senested Hansen Foundation, and the Danish Diabetes Association.

Competing interests: None declared.

1 Hales CN, Barker DJP, Clark PMS, Cox LJ, Osmond C, Winter PD. Fetal and infant growth and impaired glucose tolerance at age 64. BMJ 1991;303:1019-22

2 Phipps K, Barker DJP, Hales CN, Fall CHD, Osmond C, Clark PMS. Fetal growth and impaired glucose tolerance in men and women. Diabetologia 1993:36:225-8.

3 Lithell HO, McKeigue PM, Berglund L, Mohsen R, Lithell U-B, Leon DA. Relation of size at birth to non-insulin dependent diabetes and insulin concentrations in men aged 50-60 years. BMJ 1996;312:406-10.

4 Poulsen P, Vaag AA, Kyvik KO, Jensen DM, Beck-Nielsen H. Low birth weight is associated with NIDDM in discordant monozygotic and dizygotic twin pairs. Diabetologia 1997;40:439-46.

5 Wang X, Zuckermann B, Coffman GA, Corwin MJ. Familial aggregation of low birth weight among whites and blacks in the United States. NEngl JMed 1995;333:1744-9.

6 Skjærven R, Wilcox AJ, Øyen N, Magnus P. Mothers birth weight and survival of their offspring: population based study. BMJ 1997;314: 1376-80

7 Ramas-Arroyo MA, Ulbright TM, Yu PL, Christian JC. Twin study: relationship between birth weight, zygosity, placentation and pathologic placental changes. Acta Genet Med Gemellol 1988;37:229-38.

8 Langman J. Fetal membranes and placenta. In: Medical embryology. Baltimore: Williams and Wilkins, 1981:83-102.

9 Hales CN, Barker DJP. Type 2 (non-insulin-dependent) diabetes mellitus: the thrifty phenotype hypothesis. Diabetologia 1992;35:595-601.
10 Phillips DIW. Twin studies in medical research: can they tell us whether diseases are genetically determined? Lancet 1993;341:1008-9.

11 Hauge M. The Danish twin register. In: Mednick SA, Baert AE, Bachmann $\mathrm{BP}$, eds. Prospective longitudinal research. An empirical basis for the primary prevention of psychosocial disorders. Oxford: Oxford University Press, 1981:217-21.

12 Kyvik KO, Green A, Beck-Nielsen H. The new Danish twin register: establishment and analysis of twinning rates. Int J Epidemiol 1995;24: $589-96$

13 Poulsen P, Kyvik KO, Vaag A, Beck-Nielsen H. The heritability of non-insulin dependent diabetes mellitus (NIDDM) and abnormal glucose tolerance-a population-based twin study. Diabetologia 1999;42:139-45.

14 Magnus P, Berg K, Nance WE. Predicting zygosity in Norwegian twin pairs born 1915-1960. Clin Genet 1983;24:103-12.

15 Hemmilä I, Dakubu S, Mukkala V-M, Siitari H, Lövgren T. Europium as a label in time-resolved immunofluorometric assays. Anal Biochem $1984 ; 137: 335-43$.

16 Keen H. Diabetes diagnosis. In: Alberti KGMM, Defronzo RA, Keen H, Zimmet P, eds. International textbook of diabetes mellitus. Chichester: John Wiley,1992:19-30.

17 Cook JTE, Levy JC, Page RCL, Shaw JAG, Hattersly AT, Turner RC. Association of low birth weight with beta cell function in the adult first degree relatives of non-insulin dependent diabetic subjects. BMJ 1993;306:302-6.

18 Phillips DIW, Barker DJP, Hales CN, Hirst S, Osmond C. Thinness at birth and insulin resistance in adult life. Diabetologia 1994;37:150-4.

19 Hofman PL, Cutfield WS, Robinson EM, Bergmen RN, Menon RK, Sperling MA, et al. Insulin resistance in short children with intrauterine growth retardation. J Clin Endocrinol Metab 1997;82:402-6.

20 McKeigue PM, Lithell HO, Leon DA. Glucose tolerance and resistance to insulin-stimulated glucose uptake in men aged 70 years in relation to size at birth. Diabetologia 1998;41:1133-8.

21 Dahri S, Snoeck A, Reusens-Billen B, Remacle C, Hoet JJ. Islet function in offspring of mothers on low-protein diet during gestation. Diabetes 1991;40(suppl 2):115-20.

22 Iglésias-Barreira V, Ahn M-T, Reusens B, Dahri S, Hoet J-J, Remacle C. Pre- and postnatal low protein diet affect pancreatic islet blood flow and insulin release in adult rats. Endocrinology 1996;137:3797-801.

23 Desai M, Crowther NJ, Ozanne SE, Lucas A, Hales CN. Adult glucose and lipid metabolism may be programmed during fetal life. Biochem Soc Trans 1996;23:331-5.

24 Desai M, Crowther NJ, Lucas A, Hales CN. Organ-selective growth in the offspring of protein-restricted mothers. Br J Nutr 1996;76:591-603.

25 Holness MJ. The influence of sub-optimal protein nutrition on the insulin secretion evoked by high-energy/high-fat feeding in rats. FEBS Letters 1996;396:53-6.

26 Leger J, Levy-Marchal C, Bloch J, Pinet A, Chevenne D, Porquet D, et al. Reduced final height and indications for insulin resistance in 20 year olds born small for gestational age: regional cohort study. BMJ 1997;314:341-7

27 Robinson S, Walton RJ, Clark PM, Barker DJP, Hales CN, Osmond C. The relation of fetal growth to plasma glucose in young men. Diabetologia 1992;35:444-6.

28 Law CM, Gordon GS, Shiell AW, Barker DJP, Hales CN. Thinness at birth and glucose tolerance in seven-year-old children. Diabetic Med $1995 ; 12: 24-9$

29 Crowther NJ, Cameron N, Trusler J, Gray IP. Association between poor glucose intolerance and rapid post natal weight gain in seven-year-old children. Diabetologia 1998;41:1163-7.

(Accepted 28 April 1999)

\section{One hundred years ago The future of the woman physician}

At the graduation exercises of the Women's Medical College of the New York Infirmary held recently, Dr. Frederick Peterson, clinical professor of insanity, delivered an address on the future of the woman physician to the ladies about to embark on the treacherous sea of medical practice. Although he referred to the sweet girl graduates with curious infelicity as "Amazons," he was most gallant in his estimate of their professional accomplishments and highly optimistic as to their prospects. He foretold that "with the gradual progress of civilisation, with the slow but sure evolution of society, the work of the woman physician must unfold and broaden to an extent undreamed of now." Although at present their professional work lies chiefly among women and children, he said, there are already indications of wider fields of labour. Among these indications may perhaps be counted the elaborate study of the effects of castration and excision of the vesiculae seminales and vas deferens for tuberculosis, published not long ago in the Révue Médicale de la Suisse Romande by the Princess Guedroytz de Béloséroff, an abstract of which appeared in the Epitome of the British Medical Journal of June 24th. But Dr. Peterson seems to be looking rather to laboratory research. To the delicate manipulations of this kind of work, he says, women can bring such deft and skilful fingers that a man's awkward hands seem like the flippers of a seal in comparison. Centuries of fine needlework, crocheting, and embroidery have, he adds, prepared those fingers for section cutting, staining, and the innumerable synthetical and analytical processes required by modern methods of scientific research. (BMJ 1899;ii:105) 